\title{
Phytochemicals and Antimicrobial potential of Phyllantus amarus Schum and Thonn obtained in Ebonyi State, Nigeria
}

\author{
Stanley Chukwudozie Onuoha, Ph.D. \\ Microbiology unit, Department of Science Laboratory Technology, Akanu Ibiam Federal Polytechnic, Unwana, \\ PMB 1007 Afikpo, Ebonyi State,Nigeria .
}

\begin{abstract}
The antimicrobial efficiency of Phyllanthus amarus Schum. and Thonn, medicinal plants (leaf extracts), was examined using ethanol and chloroform as solvents and tested against human pathogens ; Staphylococcus aureus, Escherichia coli, and Candida albican, using the agar well-diffusion method and minimum inhibitory concentration. The result of the phytochemical analysis of the plant showed that the plant contain, alkaloid, tannins, steroid, saponins, phlobatannin, terpenoids and cardiac glycoside while anthraquinone was absent. The plant showed significant activity against all pathogens, but the alcoholic extract of $P$. amarus showed the maximum zone of inhibition and minimum inhibitory concentration against all the microorganisms. The alcoholic extracts of these plants could be a possible source of obtaining new and effective herbal medicines to treat infections; hence, it justified the ethnic use of P. amarus against various infectious diseases.
\end{abstract}

Keywords: Antimicrobial, Phyllantus amarus, Phytochemical, Pathogenic bacteria, Zones of inhibition.

\section{Introduction}

One of the major uses of plant apart from food, clothing, shelter and timber is its therapeutic uses (1). The medicinal value of these plants lies in bioactive phytochemical constituents that produce definite physiological action on the human body (2). The active ingredients of most of the commonly used conventional drugs were originally derived from plants parts before their pharmaceutical mass production from synthetic chemical (3 and 4).

Presently, the use of natural products ranging from drugs and foods for industrial material is increasing (5). This is because of fear of side effects, environmental pollution and other unfavourable factors that are often associated with conventional medications which are relatively reduced or even absent in natural products (6). In addition, some ailments do not have any available conventional preventive drugs. This therefore makes research in plants and other natural sources very imperative. Many locally available plants acclaimed to posses some therapeutic properties are being subjected to scientific study to ascertain the basis of their therapeutic effects and possibly be integrated into modern medicinal practice (7).

Phyllanthus amarus, member of Euphorbiaceae family was first identified in central and Southern India in $18^{\text {th }}$ century. It is commonly called carry me seed, stone -breaker, wind breaker, gulf leaf flower or gala of wind (8). There are over 300 genera with 5000 species in the Euphorbiaceae worldwide. It is a small, erect annual herb that grows $30-40 \mathrm{~cm}$ high and are highly distributed in most tropical and sub-tropical countries. The Yorubas of the South-Western Nigeria called it lyin-olobe, the Hausas in the Northern part called it geeron tsutsaayee and the Igbos of the South-East called it Ugwu ite kwowanasu.

The extract is a good blood purifier for light malaria fever and anaemia, while, the root extract is said to have therapeutic effect on Jaundice (9). P. amarus primarily contains active constituents including phyllantine and hypohyllantine, alkaloids and bioflavoniods like quercetin. Reports showed that their functions are diverse which include provision of strength to plants, attraction of insects to pollination and defense against predators, provision of colors, while some are simply waste products (9). The discovery of Phytochemicals such tannins, saponin, flavonoids, alkaloids, glycosides from $P$. amarus extracts has provide some justification for many medicinal uses of the plant. Past report on the phytochemicals and antimicrobial activities of P. amarus have been on the whole plant as it is a small herb and often used in this manner in folk medicine.

The objective of this work is to determine the phytochemicals and antimicrobial potential of the leaves and stem of $P$. amarus obtained in Afikpo, Ebonyi State, Nigeria.

\subsection{Collection and identification of Plant sample}

\section{Materials And Methods}

Fresh sample of P. amarus schum and thonn was obtained at the Botanical Garden of the Department of Science Laboratory Technology, Akanu Ibiam Federal Polytechnic, Unwana, Afikpo North Local Government Area of Ebonyi State. The plant was identified and authenticated by a botanist in the Department of Science Laboratory Technology, Akanu Ibiam Federal Polytechnic Unwana 


\subsection{Source and Maintenance of test Organisms}

Pure culture of Staphylococcus aureus, Streptococcus faecalis, Escherichia coli and P. aeruginosa clinically isolated from Rapha Medical Laboratory, Afikpo were used as test organisms. Pure cultures of the isolates were maintained in appropriate media for future use.

\subsection{Standardization of inoculums}

The inocula were prepared from the stock cultures, which were maintained on nutrient agar slant at $4^{0} \mathrm{C}$ and sub cultured onto nutrient broth using a sterilized wire loop. The density of the suspension inoculated onto the media for susceptibility test was determined by comparison with $0.5 \mathrm{McFarland}$ standard of barium sulphate solution (10)

\subsection{Preparation of the Media Used}

The media used was Mueller-Hilton Agar which was prepared according to manufacturer's instruction and sterilized by autoclaving at $121^{\circ} \mathrm{C}$ for 15 minutes at $15 \mathrm{psi}$. The sterilized media of about $15 \mathrm{ml}$ was poured into sterile plates at the angle of $45^{\circ}$ and were allowed to be solidified before use.

\subsection{Sample Preparation and Extraction}

\subsubsection{Sample preparation}

P. amarus leaves and stem were air dried at room temperature $\left(25^{\circ} \mathrm{C}\right)$ for two weeks. The dried plant material was ground with a mill grinder (standard Model No 3) into fine powder and kept in plastic container for further use.

\subsubsection{Extraction}

The powdered plant material $(50 \mathrm{~g})$ was soaked with $100 \mathrm{~mL}$ of ethanol and $140 \mathrm{~mL}$ of chloroform in $500 \mathrm{~mL}$ capacity respectively and was allowed to stay for 48 hours. After this, the mixture was stirred and carefully filtered into a $250 \mathrm{~mL}$ conical flask using whatman's No. 4 filter paper. The supernatant (extract) from the ethanol was concentrated at $50^{\circ} \mathrm{C}$ and that of chloroform at $40^{\circ} \mathrm{C}$ using water bath. The concentrated extracts were Labeled EEP (Ethanolic Extract Phyllantus), CEP (Chloroform Extract Phyllantus)

\subsection{Antibacterial Assay}

Antibacterial activity of the ethanolic and chloroform extracts of Phyllanthus amarus was individually tested against the studied organisms.

In vitro, antibacterial test was then carried out by disc diffusion method (11 and 12) using $25 \mu 1$ of standardized suspension of tested bacteria $\left(10^{8} \mathrm{cfu} / \mathrm{ml}\right)$ spread on Mueller-Hilton agar plates. The dried and sterile disc $(8 \mathrm{~mm}$ in diameter) impregnated with $0.1 \mathrm{ml}$ of standard plant extracts were placed on the seeded agar plates with the aid of sterile forceps. The plates were incubated at $37^{\circ} \mathrm{C}$ for 24 hours. Antibacterial activity was evaluated by measuring in millimeter $(\mathrm{mm})$ the zones of inhibition against the tested bacteria (11).

\subsection{Determination of Minimum Inhibitory Concentration (MIC)}

Minimum Inhibitory Concentration of the Ethanol and Chloroform extracts of the plant was determined by preparing different concentration of the extract, $25 \mathrm{mg} / \mathrm{ml}, 20 \mathrm{mg} / \mathrm{ml}, 15 \mathrm{mg} / \mathrm{ml}, 10 \mathrm{mg} / \mathrm{ml}$, and $5 \mathrm{mg} / \mathrm{ml}$. Briefly, $0.1 \mathrm{ml}$ of varying concentrations of the extracts were added into the test tubes separately containing 9 $\mathrm{mL}$ of standardized suspension of tested bacteria $\left(10^{8} \mathrm{cfu} / \mathrm{mL}\right)$. The test tubes were incubated at $37^{0} \mathrm{C}$ for $24 \mathrm{~h}$. Controls were used with the test organisms, using distilled water instead of plant extract. The least concentration of the samples with no visible growth was taken as the MIC (13).

\subsection{Phytochemical determination.}

The phytochemical analysis for qualitative detection of alkaloids, flavonoids, phlobatannins, steroids, terpenoids, and cardiac glycosides, anthraquinones and saponins was performed on the extracts as described by (14).

\section{Results}

Table 1 revealed some phytochemicals present in the leaves and stem of the plant. Phytochemicals such as saponins, steroids, phlobatanins, terpenoids, tannin, flavonoid, cardiac glycoside were found on the ethanol and chloroform extracts respectively. In the ethanolic extract of leaves, tannins, terpenoids, flavonoids, steroids and cardiac glycosides were all present, whereas, anthraquinone and phlobotannin were absent. On the other hand, in the chloroform extract, saponin, steroid, cardiac glycoside, phlobatannin and terpenoid were all present, while tannin, flavonoid and anthroquinone was absent. Observed in the ethanol extract of the stem were the following phytochemicals tannin, saponin, steroid, cardiac glycoside and terpenoid, whereas, flavonoi, 
phlobatannins and anthraquinone were absent. In the chloroform extract of the stem, tannin, saponin,steroid, phlobotanins and terpenoid were present while, flavonoid, cardiac glycoside and anthroquinone were absent

TABLE I: Phytochemical screening of leaves and stem of Phyllantus amarus

\begin{tabular}{lcccc}
\hline & \multicolumn{2}{c}{ LEA VES } & STEM \\
\cline { 2 - 5 } phytochemicals & Chloroform & Ethanol & Chloroform & Ethanol \\
\hline Tannins & - & + & + & + \\
Flavoniods & - & + & - & - \\
Saponins & + & - & + & + \\
Steroids & + & + & + & + \\
Cardiac glycosides & + & + & + & + \\
Phlobatanins & + & - & + & - \\
Terpenoids & + & + & - & + \\
Anthraquinone & - & - & & - \\
\hline
\end{tabular}

Key: $\quad+$ = present; - = Absent

Table 2 revealed diameters of zones of inhibition of bacterial and fungal growth on ethanolic and chloroform extracts of $P$. amarus.

The ethanolic extract revealed stronger antimicrobial activity against $S$. aureus with zone of inhibition as 4 $\mathrm{cm}$, E coli $4 \mathrm{~cm}$ and weak in C. albican $3 \mathrm{~cm}$ compared to that of chloroform extract. Chloroform extract of the leaves of $P$. amarus also displayed some effect against the test organisms with zones of inhibition on $S$. aureus, $3 \mathrm{~cm}$; E. coli $(3 \mathrm{~cm})$ and C. albican $(3 \mathrm{~cm})$. In this study, ethanol extract of the leaves of P. amarus revealed higher antimicrobial effect as opposed to chloroform extract of the leaves.

Table 2: Antimicrobial screening of ethanol and chloroform extract of $P$. amarus against some human pathogenic bacteria: S. aureus, E. coli and C. albican.

\begin{tabular}{lcc}
\hline & \multicolumn{2}{c}{ Zones of Inhibition diameter (cm) } \\
\cline { 2 - 3 } Organisms & Ethanol Extract & Chloroform extract \\
\hline S. aureus & 4 & 3 \\
E. coli & 4 & 3 \\
C. albican & 3 & 3 \\
\hline
\end{tabular}

Minimum Inhibitory Concentration (MIC) of the Ethanol and chloroform extracts against the tested pathogens is shown in TABLE 3 below. The highest minimum inhibition concentration was $25 \mathrm{mg} / \mathrm{ml}$ for Staphylococcus aureus and E.coil, while it is $20 \mathrm{mg} / \mathrm{ml}$ for Candida albican. The chloroform extract were also found to be susceptible to the tested pathogen; S. aureus and E. coli and their respective MIC values ranged from 20$25 \mathrm{mg} / \mathrm{ml}$.

Table 3: Minimum Inhibitory concentration of ethanol and chloroform extract of $P$. amarus against some human pathogenic bacteria: $S$. aureus, $E$. coli and $C$. albican.

\begin{tabular}{lcc}
\hline & \multicolumn{2}{c}{ Minimum Inhibitory Concentration (mg/ml) } \\
\cline { 2 - 3 } Organisms & Ethanol Extract & Chloroform extract \\
\hline S. aureus & 25 & 25 \\
& & 25 \\
E. coli & 25 & 20 \\
C. albican & 20 & \\
\hline
\end{tabular}

\section{Discussion}

The result obtained from this study showed that the chloroform and ethanol extract of Phyllantus amarus contains some bioactive agents as stated in TABLE 1. These agents are saponins, terpenoids, 
flavonoids, steroids, cardiac glycosides, phlobatannins and tannins. These agents are the effective agents of medicinal plant which have medicinal values as shown in some other studies $(15,16$ and 17)

The presence of saponins in the plant may aid in reducing the burden of the liver as regards cholesterol metabolism and in central nervous system activities. Saponins have also been reported as natural antibiotics helping the body to fight infections as well as knocking out some tumors especially blood and lung cancers ( $15,16,18)$.

Flavonoids was completely absent in the chloroform and ethanol extract of the stem but was present in the ethanol extract of the leaves. Flavonoids are antioxidants and free radical scavengers which prevent oxidative cell damage, have strong anticancer activity and protect the cell against all stages of carcinogenesis. Flavonoids in intestinal tract lower the risk of heart diseases and act as inhibitors of cyclooxygenate and 5lipoxygenase, such that additional anti-inflammatory and thrombocyte aggregation inhibitory effect can be expected (19). Terpenoids was present in the chloroform and ethanol extract of the leaves and stem of the plant. They are known to have analgesic properties. Phlobatannins was completely absent in the ethanol extracts of both leaves and stem but present in the chloroform extracts of the stem and leaves. The presence of phlobotannins serves as diuretic. The presence of terpenoids in the p. amarus extract indicated it as a natural agent for antibacterial and antifungal botanicals.

Some Glycosides are known to possess analgesic and anti-inflammatory properties. Cardiac glycosides have a strong and direct action on the heart, helping to support its strength and rate of contraction when it is failing. Cardiac glycosides are significantly diuretic.

Tannins have hypoglycemic activities. They have been reported to have astringent properties, hasten the healing of wounds and inflamed mucus membrane (18), while steroids have anti-inflammatory and analgesic properties.

The outcome of the study has also shown that the ethanol and chloroform extract of Phyllantus amarus possess antimicrobial activity. The antimicrobial activity of the plant extract against the tested pathogen varied as recorded in TABLE 2. Staphylococcus aureus and Escherichia coli showed the highest susceptibility with 4 $\mathrm{cm}$ zone of inhibition respectively, while Candida albican has $3 \mathrm{~cm}$ zone of inhibition in ethanol extract. The difference in the inhibition zone might be attributed to a more sensibility target site on the bacteria than on the C. albican by the antimicrobial agent. From the result it was observed that the chloroform extract seem to be more potent and have greater antimicrobial activity than the chloroform extract (TABLE 2). The highest zone of inhibition where found in ethanol extract of the plant. This result is justified by the report of (20) who indicated that polar solvent like ethanol were more active and can extract all the essential nutritional content of the leaves than chloroform which is a non polar or less polar and more volatile substance and therefore evaporate easily. The susceptibility of the tested organisms to extracts of Phyllantus amarus is in line with the work of $(13,22)$. The result of this research is also in agreement with the report of $(23,24)$.

The Minimum Inhibitory concentration of the chloroform and ethanol extracts of the Phyllantus amarus on the tested organisms varies as shown in TABLE 3, this show that the effect of the extracts differs from one organism to other.

\section{Conclusion and Recommendation.}

Today most pathogenic organisms are becoming resistant to antibiotics (25). To overcome this challenge, the discovery of novel active compounds against new targets is a matter of urgency. Thus, P. amarus could become promising natural antimicrobial agents with potential applications in pharmaceutical industry for controlling pathogenic organisms. However, if the plant extracts are to be used for medicinal purposes there should be improvement in approaches for natural-product isolation, characterization and synthesis, this could be opening door to a new era in the investigation of natural products in academia and industry

\section{References}

[1] Atawodi, S. E., Bulus, T. I., Ameh, S., Nok, D. A., Mammam, A. J. and Galadima, M. (2003) In vitro trypanocidal effect of methanol extract of some Nigeria savannah plants. Afr. J. biotechnol. 2(9): 317 - 321.

[2] Akinmoladun, A.C., Ibukun,E.O., Obuotor, E.M and Farombi, E.O (2007). Phytochemical constituent and antimicrobial activity of extract from leaves of Ocimum gratissimum. Sci. Res. Essay, 2:163-166.

[3] Holtz, F.B. (2002). Screening of some plants used in the Brazillian folk medicine for the treatment of infectious diseases. Oswoldo cruz. 97 (7): $1027-1031$.

[4] Odeku, O. A., Adegoke, D. A. and Majeko dunni, S (2008). Formulation of the extract of the stem bark of Alstonia booni as table dosage form. Trop. J. pharma Res. 7: $987-994$.

[5] Okeke, C. U. and Elekwa, I. (2006) comparative hypoglycemic effects of three Nigerian vegetable spices, Gongronema latifolium Benth, Allium Sativum Linn and Ocimum gratissium linn on alloxan - induced diabetic rats. Nig. J. Bot. 19 (1): 138 -146.

[6] Batista, R., Junior, A. J. S. and Oliveira, A. B. (2009). Plant derived antimalarial agents; lead and efficient phytomedicines. Part 11, Non - alkaliodal natural prod. Mol., 14: $3037-72$.

[7] Uraku, A. J., Ajah, P. M., Okaka, Ibiam A. N. C. and (2009). The effect of Vitex doniana extracts on albumin and total bilirubin of albino rats. J. Sci. Technol. $15-134$.

[8] Bharatiya, V. B. (1992). Selected Medicinal plants of India. Tafa press, Bombay, Pp: 237 
[9] Heyde, H. (1999). Medicijn plantain in Surineme. (Den dresi wiwiri foe sranen) "Medicinal plants in surineme." Vity. Stiching Gezonheisplanten informate (991) perameribo. Pp. 157

[10] Cheesbrough, M (2002). Medical Laboratory Manual for Tropical countries ELBS edition. Tropical Health Technology Publications, UK. 2: 2-392

[11] Bauer, A. W., Kirby, M. M., Sherris, J. C. and Turk, M. (1999). Antibiotic Suscetibility testing by a standard single disc method. Am J. clin pathol. $45: 483-486$

[12] Barry, A.L (1980). Procedure for testing antimicrobial agent in agar media. In Lorian V (ed) Antibiotica in Laboratory Medicines. Willims and Wikins Co. Baltimore. P. 1-23.

[13] Adesokan, A.A., Akanji, M.A and Yakubu, M.T (2007). Antibacterial potentials of aqueous extract of Enantia chlorantha stem bark. Afr. J. Biotechnol., 6(22): 2502-2505.

[14] Trease, G. E. and Evens, W. C. (2002). A Text Book of pharmacology. Academic press. London. Pp 22m - 40.

[15] Brain, R.R and Turner, T.D (1975). The practical evaluation of phytopharmaceuticals. Wright wscientia, Bristol, 57-58.

[16] Lorke, D (1983). A new approach to practical acute Toxicity testing. Arch. Toxicol, 54: 275-85

[17] Okwu, D.E and Emenike, I.N (2006). Evaluation of the phyto-nutrients and vitamin contents of the citrus fruits. Int. J. Molecular Med. Sci, 2: 1-6

[18] Stray, F (1998). The natural guide to medicinal herbs and plants, London; Tiger books international.

[19] Wagner, H. and Bladt, S. (1996). Plant Drug Analysis: A thin layer chromatography atlas. Second edition. Springer-verlay Berlin Heidebery New York Tokyo. Pp. 384.

[20] Ajaiyeoba, E (2002) Phytochemical and antibacterial properties of Parkia biglobosa leaf extracts. Afri. J. Biomed. Res., 5(1): 125129.

[21] Adesokan,A.A.,Akanji, M. A., Yakubo, M. T. (2007). Antibacterial potential of aqueous extract of Enantia chlorotha stem. Afri. J. Biotechnol. 6, 22:2502-2505.

[22] Umar, D. M. (1998). Antimicrobial activity from three fractions of M. oleifera leaves. J. Ulamic Academy of Science (1): 29 -32.

[23] Alam, O. (2006). In vivo antimicrobial activities of Quassia amara and Quassia undulata plant extracts in mice. $J$. Ethnopharmacol., 67: $321-325$.

[24] Sultana, B. F and Ashrat, M (2009). Plant from hydro alcoholic and aqueous extract of leaves and root of M. oleifera, Molecules. 14(6): $2167-2180$.

[25] Chandarana, H., Baluja, S and Chanda, S.V (2005). Comparison of antibacterial activities of selected species of Zingiberaceae family and some synthetic compounds. Turk. J. Biol, 29:83-97. 